\title{
Generation of Internal Lee Waves by Lateral Circulation in a Coastal Plain Estuary
}

\author{
XiAOHUI XIE \\ State Key Laboratory of Satellite Ocean Environment Dynamics, Second Institute of Oceanography, \\ Ministry of Natural Resources, Hangzhou, China, and Horn Point Laboratory, University of \\ Maryland Center for Environmental Science, Cambridge, Maryland \\ MING LI \\ Horn Point Laboratory, University of Maryland Center for Environmental Science, Cambridge, Maryland
}

(Manuscript received 9 July 2018, in final form 15 March 2019)

\begin{abstract}
Recent mooring observations at a cross-channel section in Chesapeake Bay showed that internal solitary waves regularly appeared during certain phases of a tidal cycle and propagated from the deep channel to the shallow shoal. It was hypothesized that these waves resulted from the nonlinear steepening of internal lee waves generated by lateral currents over channel-shoal topography. In this study numerical modeling is conducted to investigate the interaction between lateral circulation and cross-channel topography and discern the generation mechanism of the internal lee waves. During ebb tides, lateral bottom Ekman forcing drives a counterclockwise (looking into estuary) lateral circulation, with strong currents advecting stratified water over the western flank of the deep channel and producing large isopycnal displacements. When the lateral flow becomes supercritical with respect to mode- 2 internal waves, a mode- 2 internal lee wave is generated on the flank of the deep channel and subsequently propagates onto the western shoal. When the bottom lateral flow becomes near-critical or supercritical with respect to mode- 1 internal waves, the lee wave evolves into an internal hydraulic jump. On the shallow shoal, the lee waves or jumps evolve into internal bores of elevation.
\end{abstract}

\section{Introduction}

Generation of internal waves by flow-topography interactions is a long-standing topic in oceanography. Typically internal waves are generated when strong tidal currents flow over steep topographic changes such as shelf breaks (Holloway 1987; Gerkema and Zimmerman 1995; Xie et al. 2015), banks (Lamb 1994; Scotti et al. 2007) and sills (Farmer and Armi 1999; Cummins et al. 2003; Alford et al. 2015). The conversion of barotropic tidal energy to internal waves is now widely recognized as a major mechanism for mixing the ocean interior (Munk and Wunsch 1998).

In contrast, internal waves have been rarely studied in estuaries, except for flows over sills at the entrance to deep fjords (Farmer and Armi 1999; Cummins et al. 2003; Gregg and Pratt 2010) and in deep estuaries (Bourgault et al. 2007; Richards et al. 2013). In shallow coastal plain estuaries, turbulence has been mostly

\footnotetext{
Corresponding author: Xiaohui Xie, xhxie2013@gmail.com
}

attributed to boundary layer turbulence (Geyer and MacCready 2014), with little attention being paid to internal waves (Wang 2006). Dissipation by bottom friction is assumed to be the dominant sink for the barotropic tidal energy, and most studies have focused exclusively on the bottom dissipation. However, turbulence in the bottom boundary layer does not directly affect mixing across the pycnocline except through entrainment at the top of the boundary layer. Mixing in the pycnocline is an important but still unresolved process in estuaries. A few earlier observations have hinted at the presence of internal waves in coastal plain estuaries. Thermistor chain measurements by Sarabun and Dubbel (1990) revealed large-amplitude and highfrequency isotherm displacements in Chesapeake Bay. Observations in the Hudson River estuary suggested that elevated mixing may be associated with the internal waves generated by tidal flows over small-scale topography (Peters 1999). Combining moored current measurements and photographs, Groeskamp et al. (2011) observed nonlinear internal waves in the highly energetic 

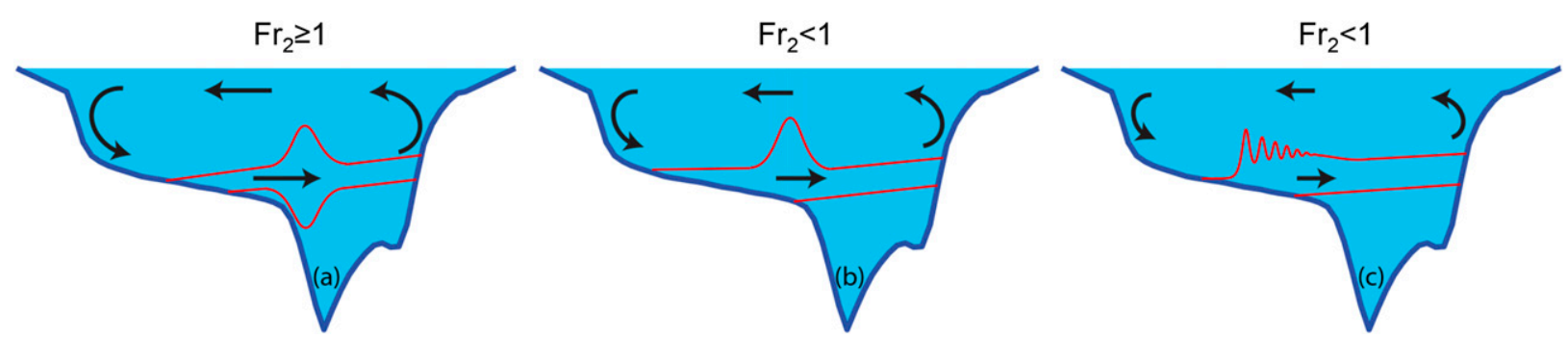

FIG. 1. A schematic diagram illustrating the generation of internal solitary waves by lateral circulation during an ebb tide (adapted from Xie et al. 2017a). Here, $\mathrm{Fr}_{2}$ is the Froude number with respect to mode-2 internal waves.

Marsdiep channel. Therefore, internal waves may play a potentially important role on internal mixing in estuaries (Wang 2006).

Recently, Xie et al. (2017a) analyzed high-resolution temperature and velocity measurements that were collected at moorings deployed in a cross-channel section of Chesapeake Bay. They observed that trains of internal solitary waves propagated shoal-ward in the crosschannel direction and had isotherm displacements of $1-3 \mathrm{~m}$ (about $20 \%$ of the water depth). The solitary waves appeared following each ebb tide and lasted $0.5-2 \mathrm{~h}$ over a tidal cycle. During one of those solitary wave events, high-resolution CTD surveys from a ship-towed undulating vehicle (Scanfish) made repeated transects near the mooring array and captured a mode- 2 internal lee wave that preceded the onset of the internal solitary waves at the mooring site on the western shore (Xie et al. 2017a). These observations suggest that an internal lee wave was generated over the edge of the deep channel, propagated westward and evolved into a train of internal solitary waves on the shallow shoal. In a related study, Xie et al. (2017b) observed large internal solitary waves under southward wind events. The vertical isotherm displacements reached 4-5 $\mathrm{m}$, occupying $30 \%$ of the water depth. The ambient cold water appeared underneath the warm (and denser) bottom water near the wave crests, indicating possible overturning and gravitational instability. The energy dissipation rate $\varepsilon$ reached $1 \times 10^{-4} \mathrm{~m}^{2} \mathrm{~s}^{-3}$ in the pycnocline during the passage of the waves, three orders of magnitude larger than the background value of $\varepsilon<1 \times 10^{-7} \mathrm{~m}^{2} \mathrm{~s}^{-3}$.

These observations raise important questions about the role of internal waves in estuaries. In the coastal ocean, nonlinear internal waves are thought to originate from the nonlinear steepening of internal lee waves or internal tides that are generated by the interaction between tidal flows and topography. However, tidal currents in coastal plain estuaries primarily move in the along-isobath direction and are thus not conducive to internal wave generation. On the other hand, coastal plain estuaries, which formed at the end of the last ice age when rising seas inundated low-lying river valleys, typically feature a deep channel flanked by shallow shoals. Could the interaction between lateral currents and channel-shoal bathymetry lead to the generation of internal waves?

Lateral currents and lateral circulation are widely observed in estuaries (Geyer and MacCready 2014). Differential advection (Nunes and Simpson 1985; Lerczak and Geyer 2004), boundary mixing on a sloping bottom (Chen and Sanford 2009), and channel curvature (Seim and Gregg 1997) are among the mechanisms known to generate the lateral circulation. In the northern Chesapeake Bay, Huijts et al. (2009) showed that lateral Ekman rectification is the dominant generation mechanism for the lateral circulation. Scully et al. (2009) found that the lateral circulation in the Hudson River estuary consists of a one-cell circulation that rotates clockwise on flood tides but counterclockwise on ebb tides. In the James River, a tributary to Chesapeake Bay, Li et al. (2017) observed a one-cell lateral circulation driven by the lateral Ekman forcing in the bottom boundary layer. In a modeling study, Li et al. (2014) investigated the strength and structure of the lateral circulation in tidally driven stratified estuaries. Without rotational effects, differential advection and diffusive boundary mixing produce two counterrotating vortices whose strength and sense of circulation may change during a tidal cycle. With rotational effects, the lateral Ekman forcing drives a one-cell lateral circulation that switches its sense of rotation over the tidal cycle.

Based on the recent observations in Chesapeake Bay and inspired by Maxworthy (1979), Xie et al. (2017a) proposed a mechanism for the generation of internal waves in coastal plain estuaries, as illustrated in the schematic diagram of Fig. 1. The lateral Ekman forcing on the ebb tidal currents generates a counterclockwise lateral circulation (looking into estuary) which advects stratified water from the western shoal to the deep channel. When this lateral flow becomes supercritical, a mode-2 internal lee wave is generated (Fig. 1a). As the lateral circulation weakens, the mode- 2 lee wave propagates westward, evolves into a mode- 1 wave of 

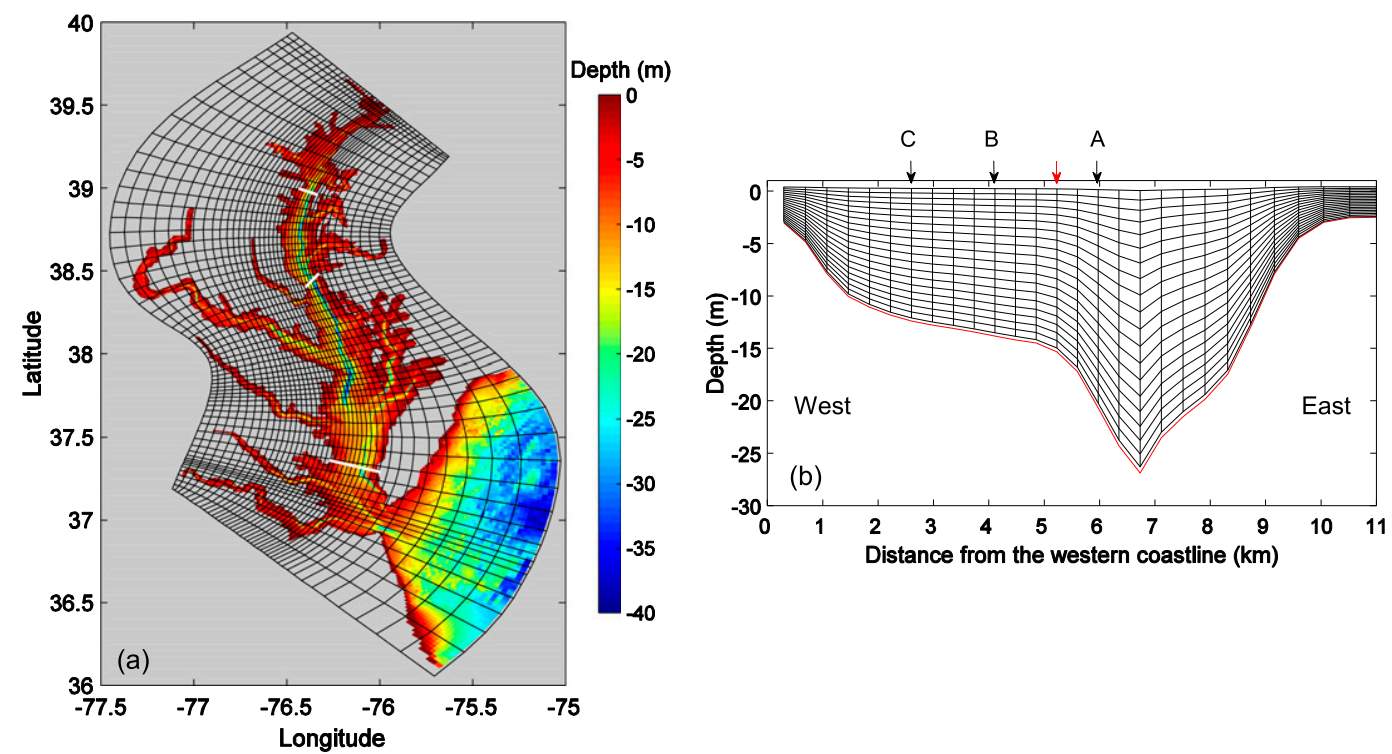

FIG. 2. (a) Map showing bathymetry of Chesapeake Bay and the grid of ROMS (showing every fourth grid cell). The white lines indicate the cross-channel sections in the upper, middle, and lower bay. The moorings were located in the cross-section in the middle bay. (b) The middle bay's cross-channel section in which the black lines mark the model grids, the red line marks the bottom bathymetry, and the black arrows mark the locations of Stations A, B, and $\mathrm{C}$ (shown in Fig. 6, below). The red arrow marks the western edge of the deep channel.

elevation (Fig. 1b), and disintegrates into a group of internal solitary waves as a result of nonlinear steepening (Fig. 1c). This modeling study is intended to test the first part of Xie et al.'s (2017a) hypothesis, namely, the generation of internal lee waves by the interaction between the lateral circulation and channel-shoal bathymetry in a coastal plain estuary.

\section{Methods}

Model simulations were performed using the Regional Ocean Modeling System (ROMS) configured for Chesapeake Bay (e.g., Cheng et al. 2013; Li et al. 2015; $\mathrm{Xie}$ and Li 2018). The model grids are $240 \times 160$ on the horizontal plane, with a horizontal grid size of $\sim 400 \mathrm{~m}$ (Fig. 2). There are 20 vertical layers. With these resolutions, the model can resolve the observed lee waves which had a horizontal scale of $\sim 2 \mathrm{~km}$ and a vertical displacement of $3-5 \mathrm{~m}$ (Xie et al. 2017a). ROMS is forced by freshwater inflows at river heads, tidal and nontidal flows at the offshore boundary, and winds and heat exchanges across the sea surface. At the upstream boundary in the eight major tributaries, freshwater inflows obtained at USGS gauging stations are prescribed. At the offshore open boundary, tidal forcing is obtained from global data-assimilative data model "TPXO7.0" (Egbert and Erofeeva 2002), and temperature and salinity are prescribed from monthly Levitus climatology (Levitus 1982). Air-sea heat fluxes are computed by applying standard bulk formulas to NARR (North America Regional Reanalysis) products (Fairall et al. 2003). The model is forced by winds measured at a variety of platforms throughout Chesapeake Bay, including the surface buoys deployed during the field experiments, CBIBS (Chesapeake Bay Interpretive Buoy System) buoys, and a network of weather stations managed by NCDC (National Climatic Data Center) and Weatherflow. These wind measurements are interpolated over the bay's surface using a universal kriging scheme (Fisher el al. 2015; Xie and Li 2018). The vertical eddy viscosity and diffusivity are computed by the $k-k L$ turbulence closure scheme with the background viscosity and diffusivity of $1 \times 10^{-6} \mathrm{~m}^{2} \mathrm{~s}^{-1}$. The horizontal eddy viscosity and diffusivity are set at $1 \mathrm{~m}^{2} \mathrm{~s}^{-1}$. The model integration lasted from 1 January 2012 to 31 October 2013 and was initialized with outputs from a hindcast simulation from 1 January 2011 to 31 December 2011.

Hydraulic theory is used to describe the flowtopography interaction and interpret the generation of internal lee waves. An important dimensionless parameter is the Froude number defined as $\mathrm{Fr}_{i}=V / C_{i}$, where $V$ is the velocity of cross-channel (lateral) flows and $C_{i}$ is the phase speed of the $i$ th mode of internal waves. The phase speed $C_{i}$ is found by solving the eigenvalue problem (Gill 1982):

$$
\frac{d^{2} \Phi(z)}{d z^{2}}+\frac{N^{2}(z)}{C_{i}^{2}} \Phi(z)=0
$$



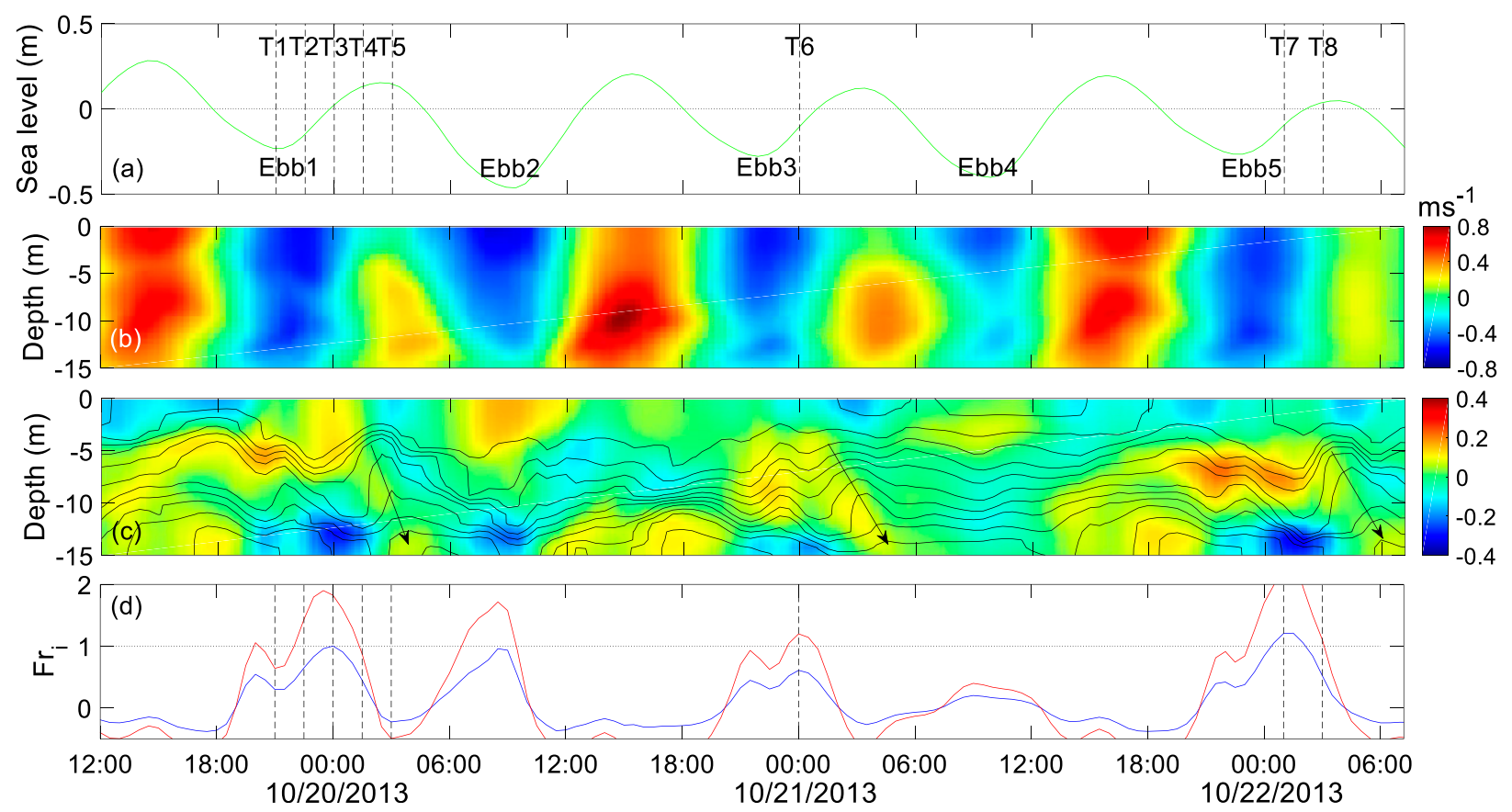

FIG. 3. Time series of (a) sea level, (b) along-channel velocity, (c) lateral velocity, and (d) Froude number of mode 1 (blue) and mode 2 (red) at the western edge of the deep channel at the middle-bay cross section (marked by the red arrow in Fig. 2). Vertical lines in (a) and (d) indicate the timing of the eight cross-channel transects $(\mathrm{T} 1, \mathrm{~T} 2, \ldots)$. Transects T1-T5 have the same time interval of $1.5 \mathrm{~h}$. In (c), the contours are $\sigma_{t}$ (density subtracted by $1000 \mathrm{~kg} \mathrm{~m}^{-3}$ ) and the black arrows highlight the vertical phase propagation of three internal lee waves.

with the boundary conditions $\Phi(0)=\Phi(-h)=0$, where $\Phi(z)$ is the modal function of the vertical velocity, $h$ is the water depth, and $N(z)$ is the background buoyancy frequency. To investigate the lateral circulation, horizontal velocities are decomposed into the alongchannel $(x)$ and cross-channel $(y)$ velocity components $u$, and $v$, respectively, on the basis of the major axis of the depth-averaged tidal flows at each grid point.
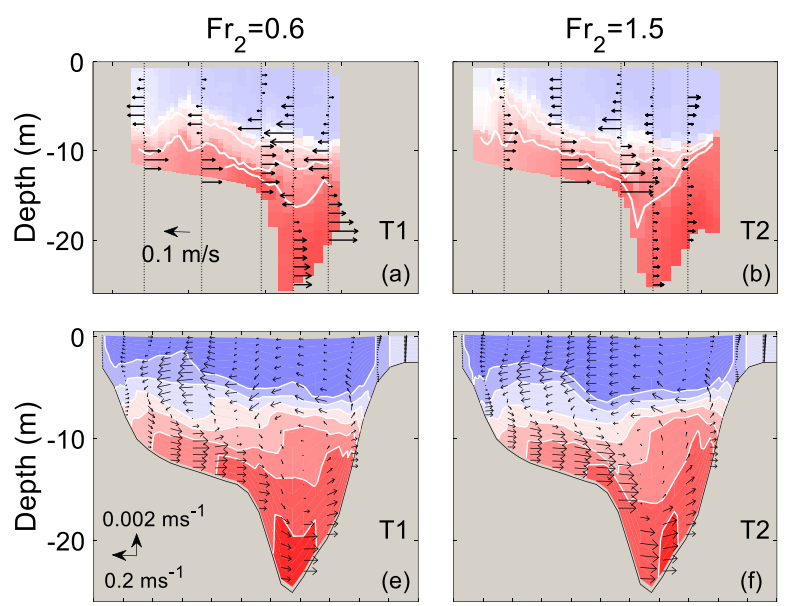

(b)
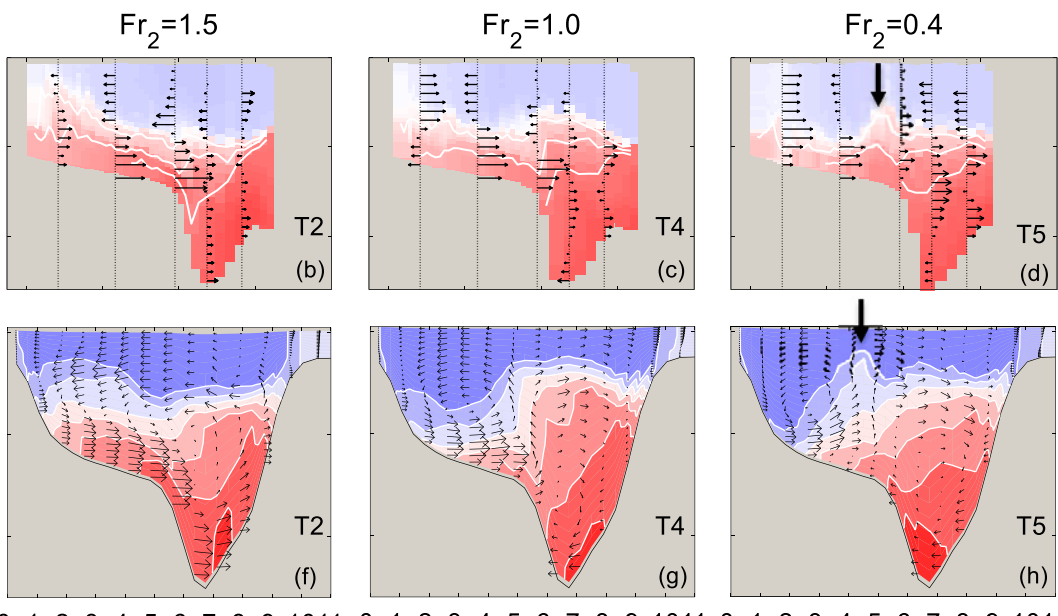

(d)

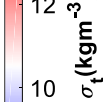

$01234567891011012334567899101101233456789101101234567891011 \quad T 10$ Distance from the western coastline $(\mathrm{km})$

FIG. 4. Cross-channel distributions of the (a)-(d) observed and (e)-(h) model-predicted lateral-vertical velocity (arrows) and $\sigma_{t}$ (colors) at four time points T1 (peak ebb), T2, T4, and T5 (shown in Fig. 3a). White contours highlight isopycnals with $\sigma_{t}$ at 10.5, 11.5, and $12.3 \mathrm{~kg} \mathrm{~m}^{-3}$. The $\mathrm{Fr}_{2}$ is calculated using the observations at the edge of the deep channel, and its value is shown on the top of (a)-(d); the $\mathrm{Fr}_{2}$ time series calculated from the model is shown in Fig. 3d. The vertical dashed lines in (a)-(d) indicate the locations of the mooring locations. The arrow in (d) and (h) points to the internal wave of elevation. 


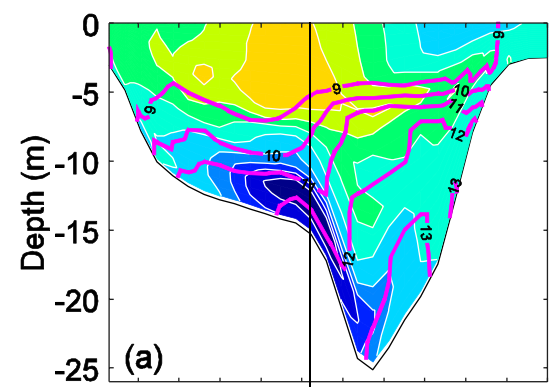

$\begin{array}{lllllllllllll}1 & 2 & 3 & 4 & 5 & 6 & 7 & 8 & 9 & 10 & 11\end{array}$

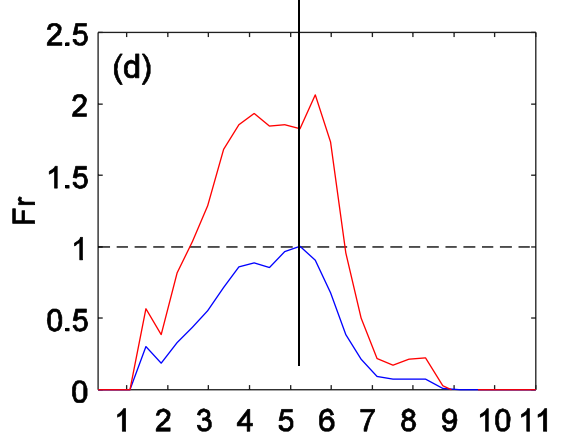

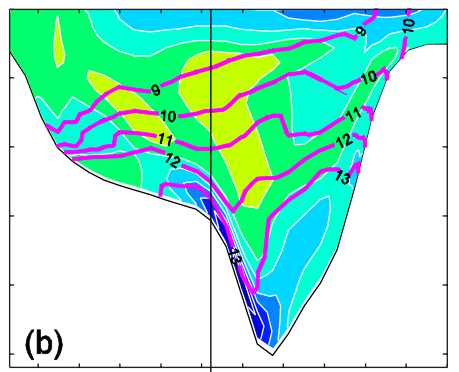
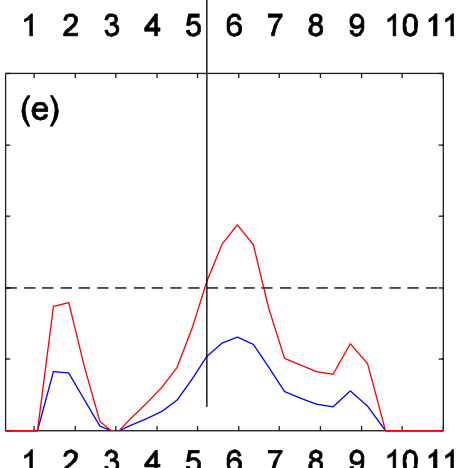

Distance from the western coastline $(\mathrm{km})$
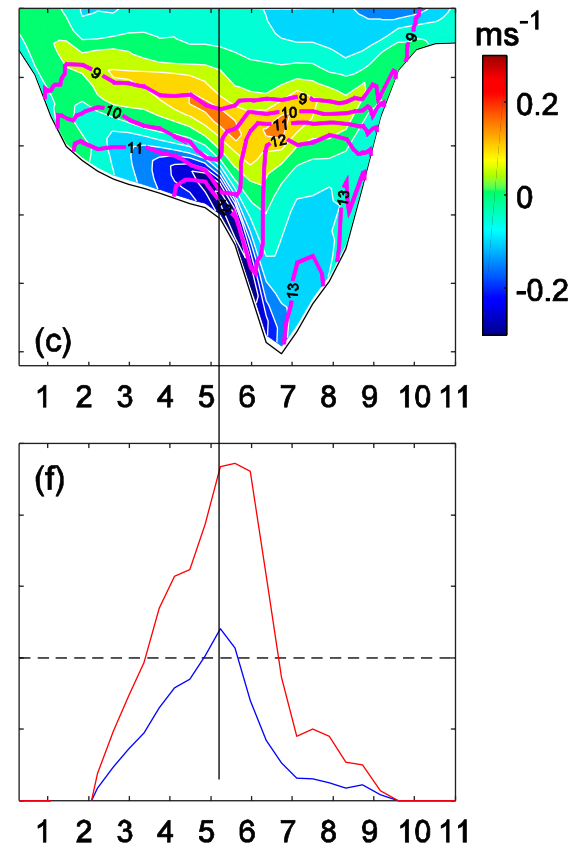

$\begin{array}{lllllllllllll}1 & 2 & 3 & 4 & 5 & 6 & 7 & 8 & 9 & 10 & 11\end{array}$

FIG. 5. Cross-channel distributions of the lateral velocity (colors) and $\sigma_{t}$ (magenta contours) at (a) T3, (b) T6, and (c) T7. Also shown are cross-channel distributions of $\mathrm{Fr}_{1}$ (blue) and $\mathrm{Fr}_{2}$ (red) at (d) T3, (e) T6, and (f) T7. Note that Fr is set to 0 when the lateral flow in the lower layer is westward. The vertical line marks the edge of the deep channel.

Since strong currents often developed at 3-4 $\mathrm{m}$ above the sea bed (Fig. 3c), the averaged lateral current speed over the bottom three layers is used to compute Fr.

\section{Results}

Mooring observations and ship surveys showed that internal lee waves were generated over the deep channel during ebb tides and propagated onto the western shore (Xie et al. 2017a). To understand the generation mechanism of the lee waves, our modeling focused on a 3-day time period in late October of 2013 when detailed observations were available for comparison. We first study the structure of the lateral circulation and then the generation and propagation of the internal lee waves.

\section{a. Lateral circulation}

Figure 3 shows the model-predicted time series of sea level, along-channel and cross-channel velocities, density, and Froude number on the western edge of the deep channel. The along-channel velocity showed the typical flood and ebb currents in an estuary, with a linear velocity profile on ebbs and a subsurface velocity maximum on floods (Fig. 3b). The maximum along-channel current was $0.8 \mathrm{~m} \mathrm{~s}^{-1}$ (Fig. 3c). This was considerably larger than the lateral current which had a magnitude of $0.1-0.3 \mathrm{~m} \mathrm{~s}^{-1}$. The lateral currents displayed a two-layer vertical structure, with the upper and lower layers flowing in opposite directions. The lateral flows in the lower layer were westward (positive) on the flood tides and eastward (negative) on the ebb tides. These currents were generated by the lateral Ekman forcing on the along-channel currents, as demonstrated by Scully et al. (2009) and Li et al. (2014). There was often a phase difference of $1-3 \mathrm{~h}$ between the peak tidal currents and maximum lateral flows (cf. Figs. $3 \mathrm{~b}$ and $3 \mathrm{c}$ ). The two-layer currents were part of the one-cell lateral circulation in the cross-channel section. During Ebb1 (at time T1 and T2), a counterclockwise lateral circulation (looking into the estuary) appeared in the crosschannel section (Figs. 4e and 4f), in general agreements with the observed lateral current structure (Figs. 4a and 4b). Although Ekman-driven lateral circulation typically consisted of a two-layer structure, the lateral flows sometimes displayed a three-layer structure (Fig. 3c), probably due to the baroclinic effects (Li et al. 2014; Xie et al. 2017c).

\section{b. Generation of internal lee waves in the lateral direction}

During the ebb tides, the eastward currents in the lower layer advected stratified water from the shallow western shoal to the deep channel, producing isopycnal displacements conducive to the generation of an internal 


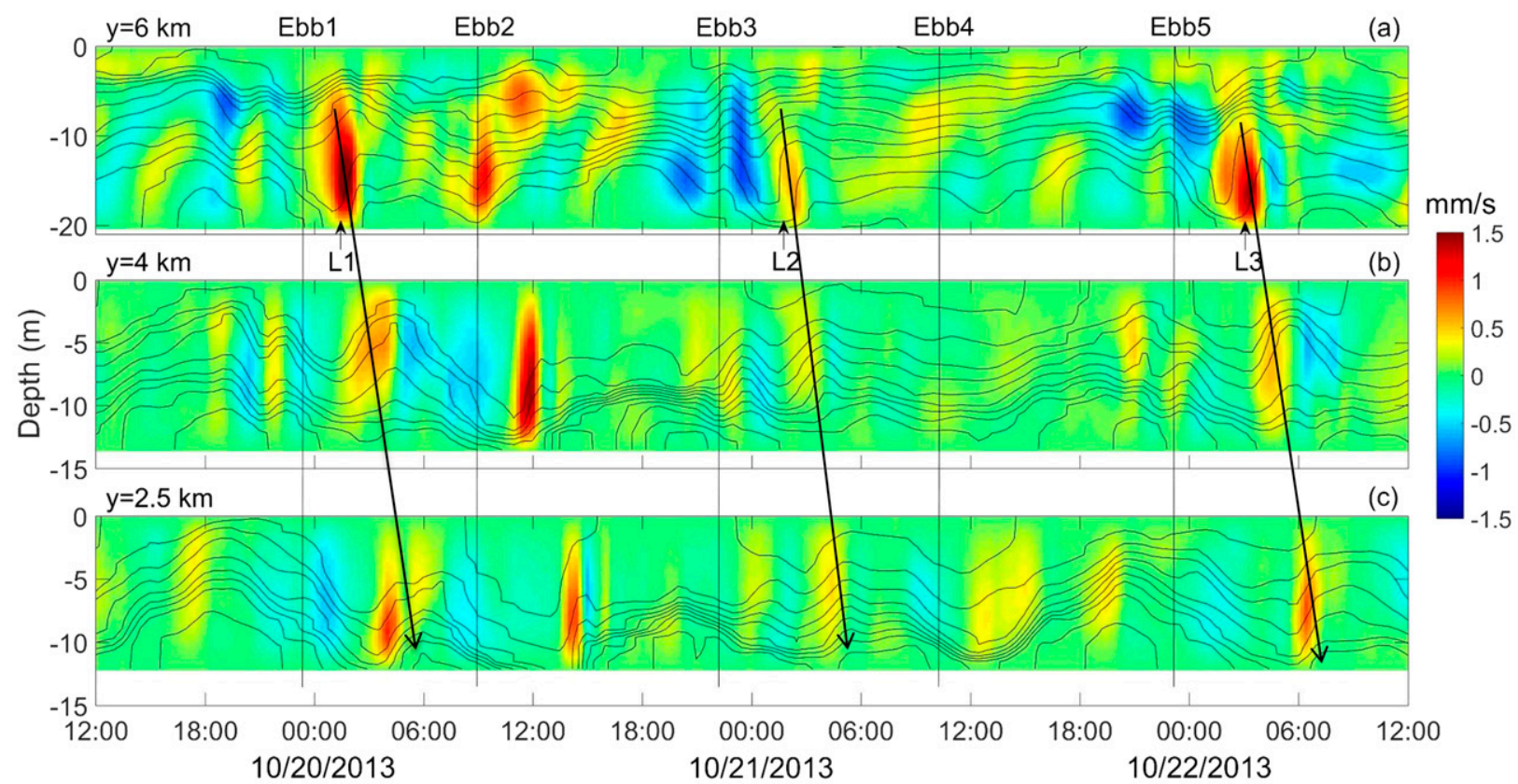

FIG. 6. Time-depth distributions of density $\sigma_{t}$ (contours) and the vertical velocity (color) at Stations (a) A, (b) B, and (c) C (marked in Fig. 2b). The oblique arrows indicate the westward propagation of the three internal lee waves. The vertical lines mark the peak ebb tides. The distance from the western coastline is given in the top-left corner of each panel. The vertical arrows in (a) mark the timing of L1-L3 shown in Fig. 7.

lee wave. Such a lee wave was captured by a ship-towed undulating vehicle (Scanfish) that made repeated crosschannel transects (a duration of $\sim 40 \mathrm{~min}$ for each transect) near the mooring array and collected fine resolution CTD data (Figs. 4a-d). Early during Ebb1 (Fig. 3a), the eastward bottom currents was subcritical (Fig. 4a). When the currents became supercritical with respect to mode-2 internal waves at the edge of the deep channel $\left(\mathrm{Fr}_{2}=1.5\right)$, a large mode-2 internal lee wave formed over the deep channel (at time T2; Fig. 4b). Later on, the lateral currents slowed down and became subcritical again $\left(\mathrm{Fr}_{2}<1\right)$. The lee wave then propagated onto the western shoal and evolved into an internal bore of elevation (at times T4 and T5; Figs. 4c,d).

This wave generation and propagation process was well simulated by the model (Figs. 4e-h). At T1 a counterclockwise circulation appeared in the crosschannel section. With $\mathrm{Fr}_{2}<1$ (Fig. 3d), no large isopycnal displacements appeared over the deep channel (Fig. 4e). At T2, the eastward lateral flows became supercritical on the western edge of the deep channel $\left(\mathrm{Fr}_{2}=1.5\right)$, and a mode-2 internal lee wave was generated over the deep channel (Fig. 4f). Subsequently, the ebb tide subsided and the lateral currents weakened. At T4 and T5 when the lateral flows became subcritical $\left(\mathrm{Fr}_{2}<1\right.$, Fig. 3d), the lee wave propagated toward the western shoal and evolved into an internal bore of elevation on the shallow western shoal (Figs. 4g,h).
Although there were quantitative differences between the observed and model-predicted current and density fields, both the model and observations showed a highly consistent process of wave generation and propagation. Moreover, both showed the steepening of the isopycnals when the lee wave crossed the western edge of the deep channel (cf. Figs. $4 \mathrm{c}$ and $4 \mathrm{~g}$ ). It is worth noting that the lateral flows peaked at $\mathrm{T} 3$ and became nearly critical with respect to mode 1 (Fig. 3d). However, the lateral flows remained subcritical at other locations (Fig. 5d). The transition from the subcritical to supercritical flows was conducive to the formation of an internal hydraulic jump, as shown in Figs. $4 \mathrm{c}$ and $4 \mathrm{~g}$.

The example shown in Fig. 4 is one of the many internal lee waves simulated by the numerical model. In four out of the five ebb tides during the 3-day time period shown in Fig. 3, strong eastward currents in the near-bottom water became supercritical on the western edge of the deep channel (Fig. 3d). Figure 5 shows one snapshot of the isopycnals during the Ebb1 (T3), Ebb3 (T6) and Ebb5 (T7). They are representative of the three flow regimes which induce different internal wave responses: $\mathrm{Fr}_{1}<1$ and $\mathrm{Fr}_{2}>1 ; \mathrm{Fr}_{1} \approx 1 ;$ and $\mathrm{Fr}_{1}>1$ (Farmer and Smith 1980). During Ebb3 (T6), a welldefined mode-2 lee wave appeared over the deep channel with $\mathrm{Fr}_{2}>1$ (supercritical with respect to mode 2) and $\mathrm{Fr}_{1}<1$ (subcritical with respect to mode 1) (Figs. 5b,e). The peak Froude numbers were reached 

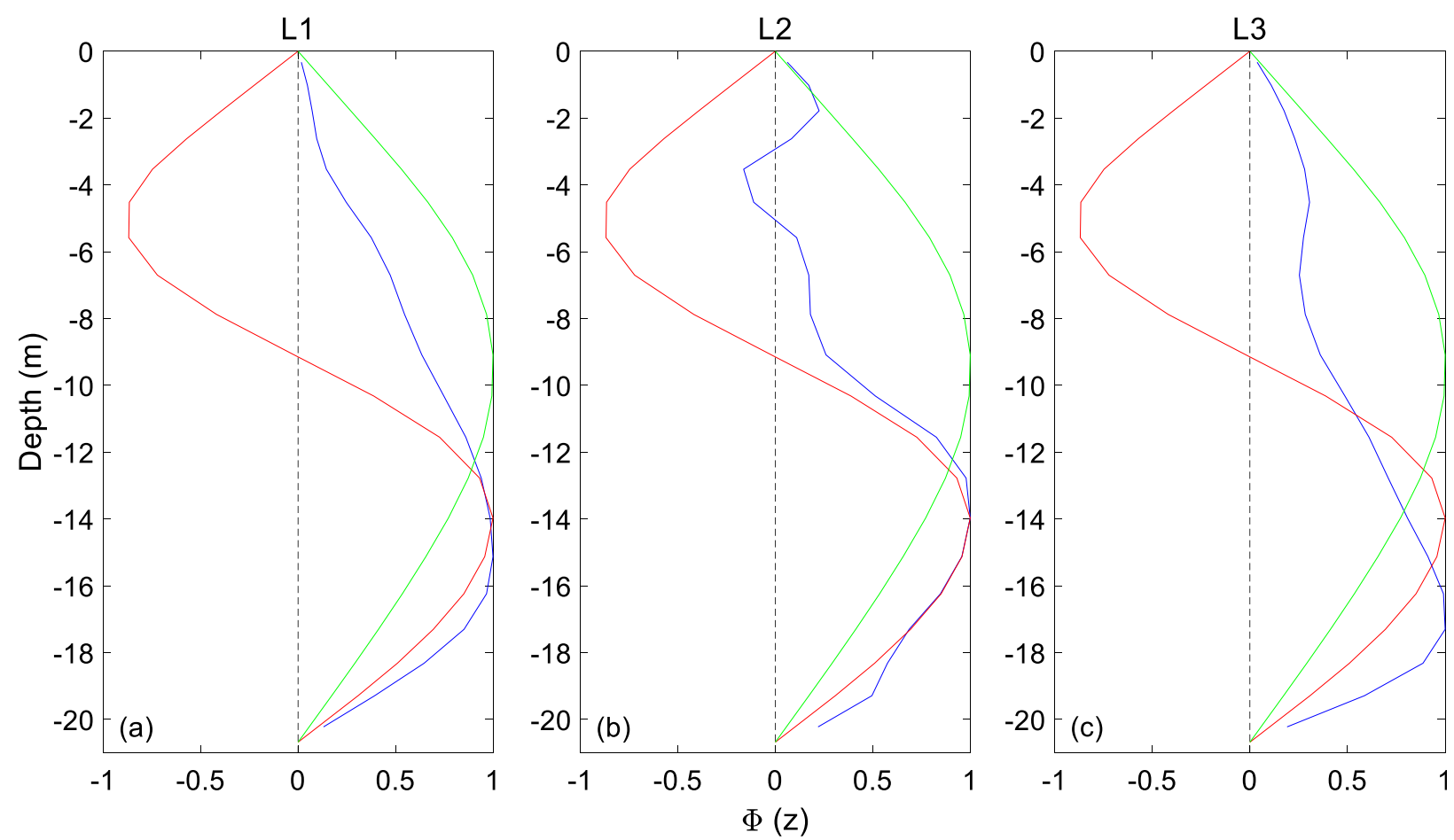

FIG. 7. Vertical profiles of the vertical velocity (blue) normalized by its maximum value at time L1, L2, and L3 shown in Fig. 6a. The green and red lines are respectively the structure function $\Phi(z)$ of mode 1 and mode 2 calculated from Eq. (1).

on the flank of the deep channel rather than at its western edge. The mode- 2 wave also emerged on Ebb1 (Fig. 4f) and Ebb 5 (not shown) when $\mathrm{Fr}_{2}>1$ and $\mathrm{Fr}_{1}<$ 1. However, as lateral flows strengthened and became supercritical with respect to mode $1\left(\mathrm{Fr}_{1}>1\right)$ on Ebb5 (T7), an internal hydraulic jump, with a rapid steepening of the isopycnals, appeared over the deep channel (Fig. 5c). The transition from the supercritical flows on the shallow western shoal to the subcritical flows in the deep channel facilitated the formation of an internal hydraulic jump (Fig. 5f). When the lateral flows were nearly critical $\left(\mathrm{Fr}_{1} \approx 1\right.$; Fig. 5d), the internal lee waves also appeared to be a hydraulic jump (Fig. 5a).

\section{c. Propagation and evolution of internal lee waves}

Next we investigate how these internal waves propagated from the deep channel to the western shore. The time-depth distributions of density and the vertical velocity at three locations are shown in Fig. 6: Station A on the western flank of the deep channel, Station B in the middle of the western shoal, and Station $\mathrm{C}$ farther west on the western shoal (their locations marked in Fig. 2b). The internal lee waves generated during the Ebb1, Ebb3 and Ebb5 propagated from the deep channel to the western shoal, with a travel time of $3-4 \mathrm{~h}$ and a propagation speed of $0.2-0.3 \mathrm{~m} \mathrm{~s}^{-1}$. Although the lee wave was a mode- 2 wave in the deep channel, it did not maintain the characteristics of a single wave mode when it propagated over the steep western flank of the deep channel (Figs. 6a and 7). The time-depth distribution of the vertical velocity at Station A showed vertical profiles of one-layer, two-layer or a composite structure, suggesting that both mode- 1 and mode- 2 waves were present. Using the least squares fitting method (Nash et al. 2005), we performed modal decomposition for the vertical velocity at Station A. The mode 1 and mode 2 explained more than $80 \%$ of the total energy for all internal lee waves. However, the relative contributions of mode- 1 and mode- 2 waves were different during different ebb tides. During Ebb1, mode 1 explained 70\% of the total wave energy and mode 2 explained $27 \%$. During Ebb3, mode 1 explained $33 \%$ and mode 2 explained $48 \%$. During Ebb5, mode 1 explained $49 \%$ and mode 2 explained $32 \%$. Although the mode- 2 wave was generated initially, the near-critical or supercritical flows with respect to mode 1 (Figs. 5d,f) could directly excite mode- 1 internal waves. Consequently, the mode1 wave dominated the wave energy during Ebb1 and Ebb5. On the other hand, wave energy could be scattered into different modes when internal waves propagated on steep bathymetry changes (Klymak et al. 2011; Kelly et al. 2013). During Ebb3, the mode-2 internal lee wave generated over the deep channel may excite 

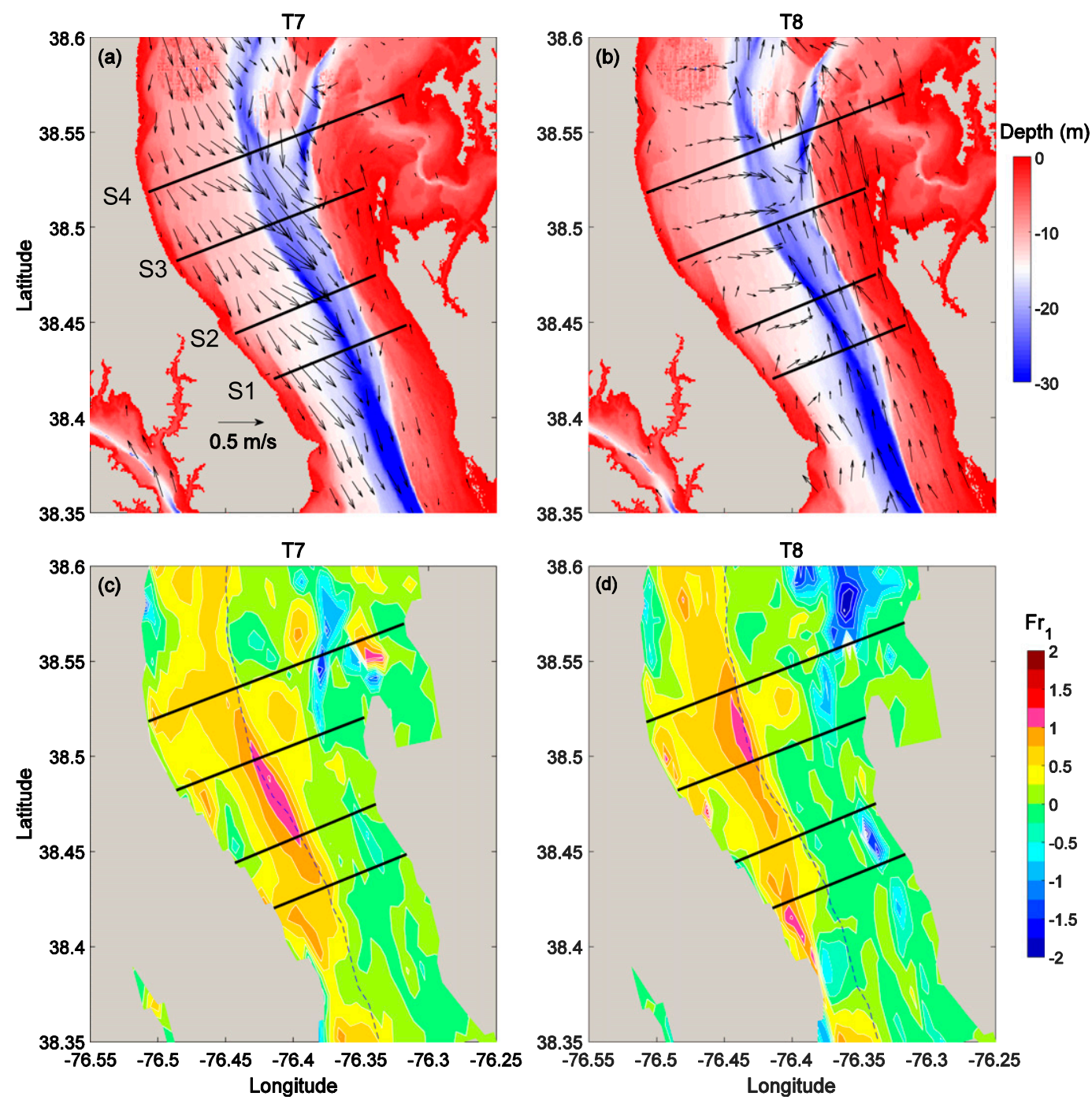

FIG. 8. Spatial distributions of the (a),(b) near-bottom current vectors (black arrows) and (c),(d) Froude number $\mathrm{Fr}_{1}$ at T7 and T8 during the fifth ebb tide (Ebb5). The bottom bathymetry is represented by color shades in (a) and (b). The dashed line in (c) and (d) marks the western edge of the deep channel. Four black lines mark the four cross-channel sections (S1-S4) analyzed in Fig. 9.

mode- 1 waves through scattering off the western flank of the deep channel. It is worth noting that the downward phase (upward energy) propagation was clear in both the density and velocity fields on the edge of the deep channel (marked by arrows in Fig. 3c), implying the presence of multiple modes. This vertical propagation is similar to the propagation of internal tides on the continental slope (Klymak et al. 2011). Note that the above modal decomposition is strictly valid only for stationary waves on a flat-bottom ocean and does not consider the effects of nonlinearity and sloping topography.

When internal lee waves propagated onto the flat western shoal (B and C sites), all of them evolved into mode- 1 waves or bores of elevation (Figs. $6 b, c)$. This indicated a transformation to mode- 1 internal bores as the lee wave propagated from the deep channel to the shallow western shoal. Stronger stratification on the shoal also supported such modal transformation. Note that the hydrostatic model cannot simulate the disintegration of the mode- 1 elevation wave into a train of internal solitary waves, as observed by Xie et al. (2017a). During the Ebb4, the lateral flows were subcritical with respect to both mode 1 and mode 2 (Fig. 3d) and no internal lee waves were generated (Fig. 6). On the other hand, Fig. 3d suggested that the lateral flows were supercritical with respect to mode 2 and nearly critical with respect to mode 1 during the Ebb2, but no internal lee waves were generated. Strong northerly winds blew 


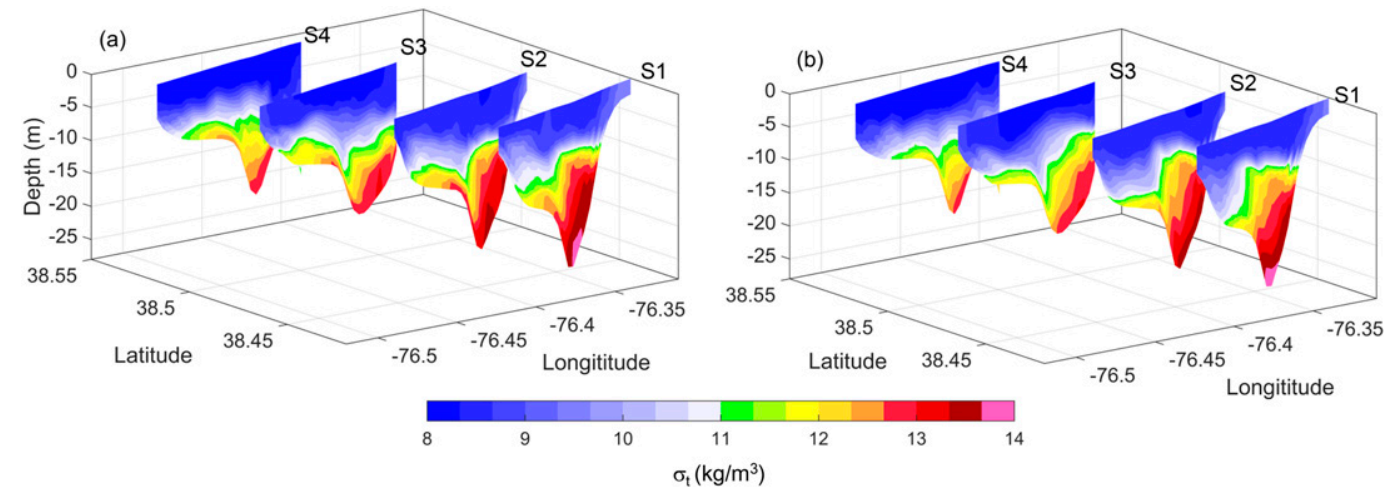

FIG. 9. Spatial distributions of density $\sigma_{t}$ at the cross-channel sections S1-S4 in the middle bay at times (a) T7 and (b) T8.

down Chesapeake Bay during the second ebb tide and likely disrupted the lateral current pattern. Observations by Xie et al. (2017b) showed that the down-estuary winds generated a gravity current in the lateral direction.

\section{d. Longitudinal variations in wave generation and propagation}

The above modeling analysis focused on the middlebay cross section where moorings were deployed. A question is raised whether the internal lee waves were also generated by the lateral circulation at other sections of Chesapeake Bay. In Fig. 8 we plot the near-bottom currents in a segment of the middle bay and examine the hydraulics of the lateral flow-topography interactions. At the peak of the Ebb5 (T7), the bottom currents veered to the left on the western shoal and the eastward lateral currents were especially strong near the western edge of the deep channel (Fig. 8a). Two hours later (T8), the currents on the western shoal flowed primarily in the lateral direction while the primary tidal current almost shut down there (Fig. 8b). This is consistent with previous modeling studies that showed a phase lag of 2-3 $\mathrm{h}$ between the maximum tidal current and peak lateral circulation strength (e.g., Li et al. 2014). Four cross-channel sections (S1, S2, S3, and S4) are marked in Fig. 8. There were differences in the timing of the maximum lateral current and peak Froude number at these sections. The southern sections S1 and $\mathrm{S} 2$ reached the supercritical flows $1-2 \mathrm{~h}$ earlier than the northern sections S3 and S4 (cf. Figs. 8c and $8 \mathrm{~d})$.

This timing difference in reaching the supercritical flow state resulted in different timings in the generation of the internal lee waves at the four sections. At T7 large isopycnal displacements appeared over the deep channel at sections S1 and S2 but the isopycnal displacements were weak at section S4 (Fig. 9a). Two hours later (T8), large isopycnal displacements appeared over the deep channel at S3 and S4 but the lee waves generated at S1 and S2 already propagated onto the shallow western shoal (Fig. 9b). The close association between the lateral flow hydraulics and the wave generation and propagation at different sections supports the hypothesis that the internal lee waves were generated by the interaction between the tidally driven lateral circulation and channel-shoal bathymetry.

\section{Discussion and conclusions}

Using a 3D hydrostatic numerical model of Chesapeake Bay, we have investigated how tidally driven lateral circulation interacted with channel-shoal topography to generate internal lee waves in a stratified estuary. It is found that a lee wave was generated over the deep channel when the lateral currents became supercritical and this lee wave propagated onto the western shore as the ebb tide weakened. The model results showed that different flow regimes may lead to different internal wave response. When $\mathrm{Fr}_{2}>1$ but $\mathrm{Fr}_{1}<1$, a mode-2 wave was initially generated over the deep channel. As lateral flows got stronger and became nearcritical or supercritical with respect to mode 1 , the mode-2 lee wave evolved into a composite wave consisting of multiple modes. Furthermore, the nearcritical or supercritical flows could also cause a rapid steepening of the lee wave, leading to a hydraulic jump. When the lee wave or jump propagated to the flat western shoal, it became a mode-1 internal bore of elevation. The model results provide a reasonable interpretation for the internal lee waves observed by Xie et al. (2017a).

Although our modeling focused on a few case studies, the internal lee waves were generated during approximately $40 \%$ of all ebb tides when the lateral circulation was strong enough to produce supercritical flows at the 


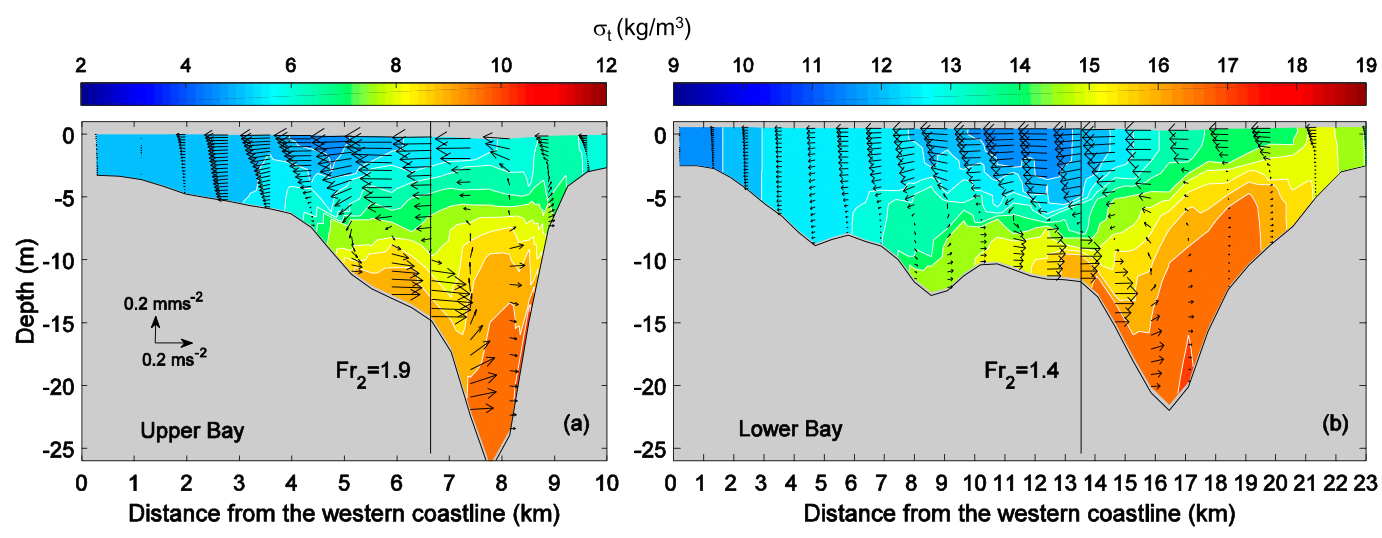

FIG. 10. Snapshots of the model-predicted lateral and vertical velocity vector (arrows) and $\sigma_{t}$ (colors) along a cross-channel section in the (a) upper and (b) lower bay marked by the white lines in Fig. 1a. The vertical line indicates the western edge of the deep channel where $\mathrm{Fr}_{2}$ is calculated.

edge of the deep channel. Lateral flows that were supercritical with respect to mode-2 wave but subcritical with respect to mode 1 wave accounted for $\sim 70 \%$ of the total wave generation. Lateral flows that were nearcritical or supercritical with respect to mode- 1 internal wave accounted for $\sim 30 \%$ of the wave generation. The numerical model also showed that the internal lee waves could be generated at cross-channel sections in the narrow upper bay and the shallow lower bay (Fig. 10). Sarabun and Dubbel (1990) reported the observations of high-frequency internal waves in the upper bay. Those high-frequency waves likely resulted from the nonlinear steepening of the internal lee waves. Therefore, the internal waves are probably prevalent over the entire Chesapeake Bay.

Winds also drive strong lateral circulation which may interact with the channel-shoal bathymetry to excite internal lee waves. However, during strong downestuary winds Xie et al. (2017b) observed the formation of a lateral bottom density front which subsequently disintegrated into large internal solitary waves. In addition, along-channel tidal currents may interact with bathymetry variations in the along-channel direction (e.g., a sill near the Rappahannock shoal at $\sim 37.7^{\circ} \mathrm{N}$ ) or changes in the orientation of the channel to generate internal waves. As shown in Xie et al. (2017b), the breaking of internal solitary waves produce turbulence dissipation rate 3-4 orders of magnitude larger than the background value. Therefore, internal waves may provide an important source for turbulent mixing in coastal plain estuaries like Chesapeake Bay.

Acknowledgments. Insightful comments from two anonymous reviewers are greatly appreciated. Author Xie is funded by NSFC (41876016 and 41621064). Author Li is grateful to NSF (OCE-1756155) for financial support.
This is University of Maryland Center for Environmental Science contribution number 5626.

\section{REFERENCES}

Alford, M. H., and Coauthors, 2015: The formation and fate of internal waves in the South China Sea. Nature, 521, 65-69, https://doi.org/10.1038/nature14399.

Bourgault, D., M. D. Blokhina, R. Mirshak, and D. E. Kelley, 2007: Evolution of a shoaling internal solitary wavetrain. Geophys. Res. Lett., 34, L03601, https://doi.org/10.1029/ 2006GL028462.

Chen, S.-N., and L. P. Sanford, 2009: Lateral circulation driven by boundary mixing and the associated transport of sediments in idealized partially mixed estuaries. Cont. Shelf Res., 29, 101-118, https://doi.org/10.1016/j.csr.2008.01.001.

Cheng, P., M. Li, and Y. Li, 2013: Generation of an estuarine sediment plume by a tropical storm. J. Geophys. Res. Oceans, 118, 856-868, https://doi.org/10.1002/jgrc.20070.

Cummins, P. F., S. Vagle, L. Armi, and D. M. Farmer, 2003: Stratified flow over topography: Upstream influence and generation of nonlinear internal waves. Proc. Roy. Soc. London, 459A, 1467-1487, https://doi.org/10.1098/rspa.2002.1077.

Egbert, G. D., and S. Y. Erofeeva, 2002: Efficient inverse modeling of barotropic ocean tides. J. Atmos. Oceanic Technol., 19, 183-204, https://doi.org/10.1175/1520-0426(2002)019<0183:EIMOBO > 2.0.CO;2.

Fairall, C. W., E. F. Bradley, J. E. Hare, A. A. Grachev, and J. B. Edson, 2003: Bulk parameterization of air-sea fluxes: Updates and verification for the COARE algorithm. J. Climate, 16, 571-591, https://doi.org/10.1175/1520-0442(2003)016<0571: BPOASF $>2.0 . \mathrm{CO} ; 2$.

Farmer, D. M., and J. D. Smith, 1980: Tidal interaction of stratified flow with a sill in Knight Inlet. Deep-Sea Res., 27A, 239-246, https://doi.org/10.1016/0198-0149(80)90015-1.

_ waves over topography. Science, $\mathbf{2 8 3}, 188-190$, https://doi.org/ 10.1126/science.283.5399.188.

Fisher, A. W., L. P. Sanford, and S. E. Suttles, 2015: Wind stress dynamics in Chesapeake Bay: Spatiotemporal variability and wave dependence in a fetch-limited environment. J. Phys. Oceanogr., 45, 2679-2696, https://doi.org/10.1175/JPO-D-15-0004.1. 
Gerkema, T., and J. T. F. Zimmerman, 1995: Generation of nonlinear internal tide and solitary waves. J. Phys. Oceanogr., 25, 1081-1094, https://doi.org/10.1175/1520-0485(1995)025<1081: GONITA $>2.0 . \mathrm{CO} ; 2$.

Geyer, W. R., and P. MacCready, 2014: The estuarine circulation. Annu. Rev. Fluid Mech., 46, 175-197, https://doi.org/10.1146/ annurev-fluid-010313-141302.

Gill, A. E., 1982: Atmosphere-Ocean Dynamics. Academic Press, $662 \mathrm{pp}$.

Gregg, M., and L. Pratt, 2010: Flow and hydraulics near the sill of Hood Canal, a strongly sheared, continuously stratified fjord. J. Phys. Oceanogr., 40, 1087-1105, https://doi.org/10.1175/2010JPO4312.1.

Groeskamp, S., J. Nauw, and L. Maas, 2011: Observations of estuarine circulation and solitary internal waves in a highly energetic tidal channel. Ocean Dyn., 61, 1767-1782, https:// doi.org/10.1007/s10236-011-0455-y.

Holloway, P. E., 1987: Internal hydraulic jumps and solitons at a shelf break region on the Australian North West Shelf. J. Geophys. Res., 92, 5405-5416, https://doi.org/10.1029/JC092iC05p05405.

Huijts, K. M. H., H. M. Schuttelaars, H. E. de Swart, and C. T. Friedrichs, 2009: Analytical study of the transverse distribution of along-channel and transverse residual flows in tidal estuaries. Cont. Shelf Res., 29, 89-100, https://doi.org/10.1016/ j.csr.2007.09.007.

Kelly, S. M., N. L. Jones, J. D. Nash, and A. F. Waterhouse, 2013: The geography of semidiurnal mode-1 internal-tide energy loss. Geophys. Res. Lett., 40, 4689-4693, https://doi.org/10.1002/grl.50872.

Klymak, J. M., M. H. Alford, R. Pinkel, R.-C. Lien, Y. J. Yang, and T.-Y. Tang, 2011: The breaking and scattering of the internal tide on a continental slope. J. Phys. Oceanogr., 41, 926-945, https://doi.org/10.1175/2010JPO4500.1.

Lamb, K., 1994: Numerical experiments of internal wave generation by strong tidal flow across a finite-amplitude bank edge J. Geophys. Res., 99, 843-864, https://doi.org/10.1029/93JC02514.

Lerczak, J. A., and W. R. Geyer, 2004: Modeling the lateral circulation in straight, stratified estuaries. J. Phys. Oceanogr., 34, 1410-1428, https://doi.org/10.1175/1520-0485(2004)034<1410: MTLCIS $>2.0 . \mathrm{CO} ; 2$.

Levitus, S., 1982: Climatological atlas of the world ocean. NOAA Professional Paper 13, 173 pp.

Li, M., P. Cheng, R. Chant, A. Valle-Levinson, and K. Arnott, 2014: Analysis of vortex dynamics of lateral circulation in a straight tidal estuary. J. Phys. Oceanogr., 44, 2779-2795, https://doi.org/10.1175/JPO-D-13-0212.1.

_ W. Liu, R. Chant, and A. Valle-Levinson, 2017: Flood-ebb and spring-neap variations of lateral circulation in the James River estuary. Cont. Shelf Res., 148, 9-18, https://doi.org/ 10.1016/j.csr.2017.09.007.

Li, Y., M. Li, and W. M. Kemp, 2015: A budget analysis of bottomwater dissolved oxygen in Chesapeake Bay. Estuaries Coasts, 38, 2132-2148, https://doi.org/10.1007/s12237-014-9928-9.

Maxworthy, T., 1979: A note on the internal solitary waves produced by tidal flow over a three-dimensional ridge. J. Geophys. Res., 84, 338-346, https://doi.org/10.1029/JC084iC01p00338.
Munk, W., and C. Wunsch, 1998: Abyssal recipes. II: Energetics of tidal and wind mixing. Deep-Sea Res. I, 45, 1977-2010, https:// doi.org/10.1016/S0967-0637(98)00070-3.

Nash, J. D., M. H. Alford, and E. Kunze, 2005: Estimating internal wave energy fluxes in the ocean. J. Atmos. Oceanic Technol., 22, 1551-1570, https://doi.org/10.1175/JTECH1784.1.

Nunes, R., and J. Simpson, 1985: Axial convergence in a well-mixed estuary. Estuar. Coast. Shelf Sci., 20, 637-649, https://doi.org/ 10.1016/0272-7714(85)90112-X.

Peters, H., 1999: Spatial and temporal variability of turbulent mixing in an estuary. J. Mar. Res., 57, 805-845, https://doi.org/ 10.1357/002224099321514060.

Richards, C., D. Bourgault, P. S. Galbraith, A. Hay, and D. E. Kelley, 2013: Measurements of shoaling internal waves and turbulence in an estuary. J. Geophys. Res., 118, 273-286, https://doi.org/10.1029/2012JC008154.

Sarabun C. C., and D. C. Dubbel, 1990: High-resolution thermistor chain observations in the upper Chesapeake Bay. Johns Hopkins APL Tech. Dig., 11, 48-53.

Scotti, A., R. C. Beardsley, and B. Butman, 2007: Generation and propagation of nonlinear internal waves in Massachusetts Bay. J. Geophys. Res., 112, C10001, https://doi.org/10.1029/ 2007JC004313.

Scully, M. E., W. R. Geyer, and J. A. Lerczak, 2009: The influence of lateral advection on the residual estuarine circulation: A numerical modeling study of the Hudson River estuary. J. Phys. Oceanogr., 39, 107-124, https://doi.org/10.1175/2008JPO3952.1.

Seim, H. E., and M. C. Gregg, 1997: The importance of aspiration and channel curvature in producing strong vertical mixing over a sill. J. Geophys. Res., 102, 3451-3472, https://doi.org/ 10.1029/96JC03415.

Wang, D., 2006: Tidally generated internal waves in partially mixed estuaries. Cont. Shelf Res., 26, 1469-1480, https://doi.org/ 10.1016/j.csr.2006.02.015

Xie, X., and M. Li, 2018: Effects of wind straining on estuarine stratification: A combined observational and modeling study. J. Geophys. Res., 123, 2363-2380, https://doi.org/10.1002/ 2017JC013470.

—, Y. Cuypers, P. Bouruet-Aubertot, A. Pichon, A. Lourenço, and B. Ferron, 2015: Generation and propagation of internal tides and solitary waves at the shelf edge of the Bay of Biscay. J. Geophys. Res., 120, 6603-6621, https://doi.org/10.1002/ 2015 JC010827.

—, M. Li, M. E. Scully, and W. C. Boicourt, 2017a: Generation of internal solitary waves by lateral circulation in a stratified estuary. J. Phys. Oceangr., 47, 1789-1797, https://doi.org/ 10.1175/JPO-D-16-0240.1.

— — - - and W. C. Boicourt, 2017b: Breaking of internal solitary waves generated by an estuarine gravity current. Geophys. Res. Lett., 44, 7366-7373, https://doi.org/10.1002/ 2017GL073824.

- $—$, and,$- 2017 \mathrm{c}$ : Baroclinic effects on wind-driven lateral circulation in Chesapeake Bay. J. Phys. Oceanogr., 47, 433-445, https://doi.org/10.1175/JPO-D-15-0233.1. 